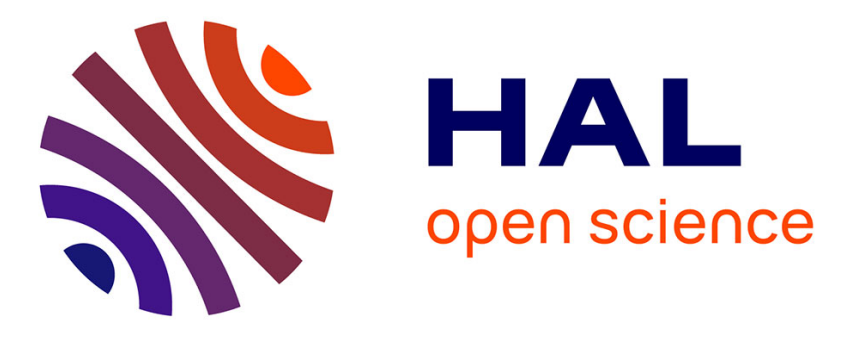

\title{
IR emission from the target during plasma magnetron sputter deposition
}

\author{
P.-A. Cormier, A.-L. Thomann, Vincent Dolique, A. Balhamri, R. Dussart, N. \\ Semmar, T. Lecas, P. Brault, R. Snyders, S. Konstantinidis
}

\section{To cite this version:}

P.-A. Cormier, A.-L. Thomann, Vincent Dolique, A. Balhamri, R. Dussart, et al.. IR emission from the target during plasma magnetron sputter deposition. Thin Solid Films, 2013, 545, pp.44-49. 10.1016/j.tsf.2013.07.025 . in2p3-00874718

\section{HAL Id: in2p3-00874718 https://hal.in2p3.fr/in2p3-00874718}

Submitted on 15 Nov 2013

HAL is a multi-disciplinary open access archive for the deposit and dissemination of scientific research documents, whether they are published or not. The documents may come from teaching and research institutions in France or abroad, or from public or private research centers.
L'archive ouverte pluridisciplinaire HAL, est destinée au dépôt et à la diffusion de documents scientifiques de niveau recherche, publiés ou non, émanant des établissements d'enseignement et de recherche français ou étrangers, des laboratoires publics ou privés. 


\title{
IR emission from the target during plasma magnetron sputter deposition
}

P-A Cormier ${ }^{1}$, A-L Thomann ${ }^{1 *}$, V. Dolique ${ }^{2}$, A. Balhamri ${ }^{3,4}$, R. Dussart ${ }^{1}$, N.Semmar ${ }^{1}$, T. Lecas $^{1}$, P. Brault ${ }^{1}$, R. Snyders ${ }^{3,5}$ and S. Konstantinidis ${ }^{5}$

${ }^{1}$ GREMI, Université d'Orléans, 14 rue d'Issoudun, B.P. 6744, 45067 ORLEANS Cedex2, France

${ }^{2}$ LMA, Université Claude Bernard Lyon I 7 avenue Pierre de Coubertin, 69622VILLEURBANNE Cedex, France

${ }^{3}$ ChIPS, Université de Mons, 20 place du parc, 7000 Mons, Belgique

${ }^{4}$ Université Hassan 1, École Supérieure de Technologie, 218 Berrechid, Maroc

${ }^{5}$ Materia Nova R\&D Center, Avenue Corpernic 1, Mons, Belgium

Corresponding author:

Tel: +33(0)2-38-41-70-01; Fax: +33(0)2-38-41-71-54

e-mail: anne-lise.thomann@univ-orleans.fr

\begin{abstract}
In this article, energy flux measurements at the substrate location are reported. In particular, the energy flux related to IR radiation emanating from the titanium $(10 \mathrm{~cm}$ in diam.) target surface is quantified during magnetron sputter deposition processes. In order to modulate the plasma-target surface interaction and the radiative energy flux thereof, the working conditions were varied systematically. The experiments were performed in balanced and unbalanced magnetic field configurations with Direct Current (DC), pulsed DC and High Power Impulse Magnetron Sputtering (HiPIMS) discharges. The power delivered to the plasma was varied too, typically from 100 to $800 \mathrm{~W}$. Our data show that the IR contribution to the total energy flux at the substrate increases with the supplied sputter power and as the discharge is driven in a pulse regime. In the case of HiPIMS discharge generated with a balanced magnetic field, the energy flux associated to the IR radiation produced by the target becomes comparable to the energy flux originating from collisional processes (interaction of plasma particles such as ions, electron, sputtered atoms etc. with the substrate). From IR contribution, it was possible to estimate the rise of the target surface temperature during the sputtering process. Typical values found for a titanium target are in the range $210^{\circ} \mathrm{C}$ to $870^{\circ} \mathrm{C}$.
\end{abstract}

Keywords: magnetron sputter deposition, superficial target heating, IR emission, energetic contributions at the substrate 


\section{Introduction}

Cold plasma based magnetron sputtering is one of the work horse of the coating industry. Magnetron sputtering offers various advantages such as low pollution level and precise control of the coating chemistry and microstructure which, in fine, determine the final properties of the coated surfaces [1]. It is well known that film features, and especially crystallinity and microstructure, widely depend on the energy delivered to the substrate and the thin film during the growth process [2]. During magnetron sputter deposition, the energy can be supplied through bombardment by ions, neutrals, electrons, photons, and/or through intentional heating of the substrate on its backside.

On the other hand, the sputter target top most surface is always heated during the sputtering process, even if it is properly cooled, as it is bombarded by the plasma ions accelerated in the cathode sheath. In most cases, IR emission from the hot target surface is completely ignored as its interaction with the growing film. One of the main reason lie in the difficulty to evidence such energetic contribution by conventional discharge diagnostics [3]. Nevertheless, IR photons can be absorbed by the growing film relatively efficiently depending on the optical properties of the latter. This was suggested by Mercs et al. in the case of the deposition of $\mathrm{Al}_{2} \mathrm{O}_{3}$ thin films by reactive magnetron sputtering from a hot (i.e. not cooled) aluminum target [3], although no quantification of the IR radiation flux was reported.

In this work, the energy delivered to the growing film was directly measured during magnetron sputter deposition processes. An energy flux diagnostic tool specially designed for low-pressure plasma processes was used [4]. The sensitivity and the accuracy of this tool were previously demonstrated in several plasma systems [4-7]. It has been shown that, thanks to the fast time response of the sensor (thermopile), the energetic contribution of the plasma can be separated from thermal processes such as IR emission from the heated target. The aim of this work was to determine how the plasma-cathode surface interaction influences the radiative energy flux at the substrate position. Therefore, the evolution of the heat flux attributed to IR photons was studied as a function of the cathode magnetic field configuration, the discharge type, and the sputter power. The energetic contribution due to IR emission was quantified in terms of magnitude and kinetics. Finally the temperature of the sputter target was deduced for each working conditions. 
2. Experimental procedure

The diagnostic is based on a commercial Heat Flux Micro sensor (Vattell-HFM-7). The HFM is composed of a thermopile sensor (approx. $6 \mathrm{~mm}$ in diameter) which provides a voltage variation directly proportional to the incoming energy flux density. It is calibrated according to a NIST protocol based on IR radiation emitted from a black body [4]. The HFM voltage was registered every $0.5 \mathrm{~s}$ using a nanovoltmeter (Keithley 2182). In order to avoid any radiation losses by IR emission from the sensor itself, the HFM was water-cooled down to $5^{\circ} \mathrm{C}$. Since the sensor temperature is not allowed to rise, a clear positive energy flux is always measured. A $6 \mathrm{~mm}$ diameter copper substrate was glued on the HFM active area using a thermally conductive paste. Previous works have shown that this copper plate does not disturb the measurements $[6,8]$.

The energy flux diagnostic was mounted in a conventional magnetron sputtering experiment dedicated to the deposition of titanium films. Energy flux measurements were performed $8 \mathrm{~cm}$ away from a water-cooled, $10 \mathrm{~cm}$ in diameter, $6 \mathrm{~mm}$ - thick, titanium target. DC magnetron (DCMS), pulsed DC magnetron (pDCMS) and High Power impulse Magnetron Sputtering (HiPIMS) discharges were ignited successively. More details about the experimental setup and the HiPIMS pulse can be found in [9] and [10]. To study the influence of each discharge type, pressure and averaged power were set to $0.66 \mathrm{~Pa}$ (Argon) and $400 \mathrm{~W}$, respectively. Discharge parameters are given in table 1 for HiPIMS and pDCMS. In each case the magnetic field configuration was either balanced (B) or unbalanced (UB). The field lines corresponding to these two magnetron cathodes are reported on fig. 1 . The strength of the parallel component of the magnetic field, $\sim 1 \mathrm{~cm}$ from the target surface, equals $\sim 300 \mathrm{G}$ for the unbalanced magnetron cathode, while it equals $\sim 400 \mathrm{G}$ in the case of the balanced magnetron cathode. The magnetic field trap is therefore more efficient in the case of the balanced discharge. For a given target voltage, the discharge current and the ion bombardment are thus increased for this latter case. On Fig 1, the substrate (or energy flux probe) position is also indicated. Measurements were also carried out in DCMS, 0.66 Pa and at various powers in the $100 \mathrm{~W}$ to $800 \mathrm{~W}$ range.

3. IR contribution and target temperature

As it was previously demonstrated, HFM measurements allow separating contributions exhibiting different time scales [7]. Figure 2a shows a typical HFM signal which represents the evolution of the energy flux with respect to time in the case of a balanced pDCMS 
discharge. A rapid energy deposition (hundreds to thousands of $\mathrm{mW} . \mathrm{cm}^{-2}$ per s) is detected when the plasma is switched on. This rise lasts about $1 \mathrm{~s}$, which is the time resolution of our data acquisition system. This first rise is mainly attributed to plasma energetic particles such as charged particles (electrons and ions), sputtered atoms, fast neutrals ... The quantification of each of these contributions and their relative importance was previously carried out in the case of cathodic plasma sputtering experiments [7].

This sharp increase of the heat transfer is followed by a slower one (1.4 mW.cm² per s). A saturation of the heat signal is finally reached after approximately $10 \mathrm{~s}$. This time scale is typical of a gradually heating body [5] that emits IR radiations. During plasma magnetron sputtering processes, it is expected that the target surface, located in front of the substrate (or the HFM), is heated by the intense ion bombardment. The grounded chamber walls may also be heated up, however the temperature rise of the chamber walls (and other pieces of the equipment) is significantly limited: i) as particle bombardment is dramatically limited on these parts and ii) due to geometrical considerations. The assumption that the slow increase monitored at the substrate level is due to a thermal process is corroborated by the slow decrease $\left(2 \mathrm{~mW} . \mathrm{cm}^{-2}\right.$ per s) of the heat flux that is observed as soon as the sputtering plasma is switched off. The intensity of the IR radiation emitted by the target surface should slowly decrease as soon as the later starts to cool down.

It is seen on Fig. 2a that the signal related to the IR emission from the target saturates. At this point, thermal equilibrium is reached at the target surface. This may take a relatively long time to appear. Rough estimations of the contact thermal resistance of the system which is constituted of the thermal paste (Jelt compound silicone paste: $0.009 \mathrm{~W} . \mathrm{cm}^{-1} \mathrm{~K}^{-1}$ ), the $\mathrm{Cu}$ plate $\left(0.5 \mathrm{~W} . \mathrm{cm}^{-1} \mathrm{~K}^{-1}[11]\right)$, and the growing layer $\left(0.219 \mathrm{~W} \cdot \mathrm{cm}^{-1} \mathrm{~K}^{-1}\right.$ for Ti for example [12]), have shown that the energy flux measurements remain valid even if a thick metal layer of 10 $\mu \mathrm{m}$ is deposited on the sensor. However, in order to avoid any drift of the measured signal, we tried to limit the acquisition time. Consequently, for an accurate estimation of the IR contribution, experimental data were fitted (black line in Fig. 2a) by solving the heat balance equation at the substrate (i.e. the probe) surface [5]. The equation 1 describes the evolution of the total heat flux at the HFM surface $\left(\varphi_{\text {tot }}\right)$ with respect to time, assuming an offset value $\left(\varphi_{0}\right)$ which is the sum of the radiative transfer between the substrate surface at $5^{\circ} \mathrm{C}\left(\varphi_{5^{\circ}} \mathrm{C}\right)$ and the wall at ambient temperature, and the energy flux due to collisional processes ( $\varphi_{\text {coll }}$ (initial sharp rise)): 


$$
\varphi_{\text {tot }}=\varphi_{0}+\varphi_{\text {radeq }}\left(1-\exp \left(\frac{-t}{\tau}\right)\right)
$$

Where $\varphi_{\text {radeq }}$ is the amplitude of the energy flux increase during the thermal process, and $\tau$ is the characteristic time, which stands for the rate of heating of the target surface. When $\tau$ increases, a longer time is needed to reach the thermal equilibrium.

This characteristic time can be deduced from a heat balance in the unsteady regime established on the target surface. In this way, the time evolution of the measured energy flux density depends on the time evolution of the target surface temperature. Namely:

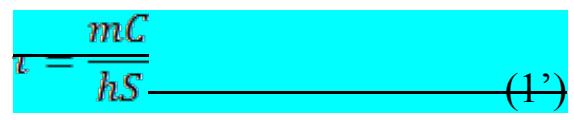

\section{Where $\mathrm{mC}$ is the heat capacity of the target, $\mathrm{S}$ the heat exchange surface, and $\mathrm{h}$ a global heat} eoefficient, that is proportional to the cathode thermal conductance. In our case (low pressure environment) the heat exchange is dominated by radiation and conduction throughout the cathode. Therefore the h parameter mostly depends on $\tau$ is related to the emissivity of the target material, and on the manner that the target is clamped on the cooled cathode.

On figure 2a, all the parameters used in the equation 1 are detailed. For the corresponding signal $\varphi_{\text {rad }}=65 \mathrm{~mW} / \mathrm{cm}^{2}$ and this value stands for $15 \%$ of the global energy transferred to the substrate.

From the IR radiation detected at the substrate, the target surface temperature can be roughly estimated using the radiative heat flux equation between the metal target (Met) and the cooled copper $(\mathrm{Cu})$ plate (eq. 2$)$ :

$$
\varphi_{\text {rad }}=f_{M e t / C u} \sigma\left(\varepsilon_{M e t} T_{M e t}^{4}-\varepsilon_{C u} T_{C u}^{4}\right)
$$

Where $\varphi_{\text {rad }}$ is the measured energy flux due to IR emission when the thermal equilibrium is reached ( $\varphi_{\text {radeq }}$ of the equation 1$) . f_{\mathrm{Met} / \mathrm{Cu}}$ denotes the geometrical factor taking into account that only a portion of the target IR emission can be detected by the HFM. $\sigma=5.67 \times 10^{-8} \mathrm{~W} . \mathrm{m}^{-}$ ${ }^{1} \mathrm{~K}^{-1}$ is the Stefan-Boltzmann constant and $\varepsilon_{\mathrm{Met}}$ and $\varepsilon_{\mathrm{Cu}}=0.5$ are the total emissivities of target material and oxidized copper [13], respectively. $\mathrm{T}_{\mathrm{Met}}$ and $\mathrm{T}_{\mathrm{Cu}}$ represent target and copper 
substrate temperatures, respectively. $\mathrm{T}_{\mathrm{cu}}$ is assumed to be at the same temperature as the cooled HFM, i.e. $5^{\circ} \mathrm{C}$.

In the case of the deposition of titanium thin films $\mathrm{f}_{\mathrm{Met} / \mathrm{Cu}}=0.1011$ and $\varepsilon_{\mathrm{Met}}=0.5$. For a pDCMS discharge at $400 \mathrm{~W}$ and $0.66 \mathrm{~Pa}$ (Fig. 2a) the temperature reached by the Ti target surface is estimated to $420^{\circ} \mathrm{C}$.

4. Results and discussion

4.1. Magnetic configuration and discharge type

Figure $2 \mathrm{~b}$ shows the HFM signal for a balanced (B) and a pDCMS discharge in the same working conditions than in Fig. 2a. Energy fluxes due to collisional processes are approximately 5 times higher in the UB case than in B magnetron sputtering experiments (Fig. 1). This was expected since with the UB configuration, the field lines are opened towards the substrate. Consequently, the charged particles are steered to the substrate where the energy is finally deposited. Inversely, with the B configuration, the plasma is confined close to the target surface and less energy is delivered by the plasma particles to the growing film. The magnetic field strength is also higher. However, in this case, the ion bombardment at the target surface is increased. This situation should lead to a more significant heating of the later, and thus to an enhanced IR contribution at the substrate location. This is what is observed in Fig. 2. The IR contribution equals $15 \%$ and $3 \%$ of the total energy flux provided to the substrate during pDCMS in B and UB configurations, respectively.

Fig. 3 presents the energy flux densities recorded for the three different discharge types for the balanced magnetic field, a pressure of $0.66 \mathrm{~Pa}$, and an averaged power of $400 \mathrm{~W}$. It can be noted that IR contribution is very large during the HiPIMS discharge (Fig. 3c) for which the peak target current and power densities are typically 2 to 3 orders of magnitude larger than in DCMS discharges [14]. Indeed, with the B field configuration, energy fluxes at the thermal equilibrium were estimated to 360,441 , and $667 \mathrm{~mW} . \mathrm{cm}^{-2}$ for DCMS, pDCMS, and HiPIMS discharges, respectively. During the B HiPIMS discharge, IR contribution represents up to 95 $\%$ of the global value!

The characteristic time could also be determined from the fit of the IR contribution using equation (1). The corresponding values are 6, 9 and $289 \mathrm{~s}$, for DCMS, pDCMS and HiPIMS, respectively. In cases of DCMS and pDCMS, where the duty cycles are nearly the same (see on table 1), these values are in the same order of magnitude. $\tau$ is the highest in the HiPIMS 
case, where the duty cycle is very low (4\%). As mentioned above, the kinetics of the IR emission is related to the heating rate of the target surface (depending on the incoming energy flux, target thermal conductivity and cooling efficiency). The very high value of $\tau$ obtained for HiPIMS, i.e. the long time to reach the thermal equilibrium at the target surface, can be explained by: i) the fact that a huge energy flux is deposited during a short pulse; ii) the fact that the target surface cooling down during the long pulse OFF time is not efficient. Indeed, titanium is characterized by a relatively small heat conductivity $(21.9 \mathrm{~W} / \mathrm{mK})$ [12]. Moreover, if cooling by gas convection weakly takes place, this process is less efficient in HiPIMS discharges for which the strong sputtering wind is known to induce a local gas depletion, further reducing the gas pressure close to the target surface (see Ref 1 and references therein). The corresponding surface temperatures were estimated from equation (2). They were found equal to 362,420 , and $870^{\circ} \mathrm{C}$ for DCMS, pDCMS, and HiPIMS discharges, respectively. The results highlight that a significant increase of the target surface temperature occurs in each sputtering regime. This rise is promoted in pulsed processes and especially in the HiPIMS one. A significant increase of the target temperature in HiPIMS processes has already been reported [15]. In literature IR emitted by the target is sometimes envisaged, but usually no quantification is given and the possible effect on the growth process is rarely discussed. If the temperature is sufficiently high to induce a modification of the target material properties such as its secondary electron emission coefficient, the discharge parameters could be modified, and the increase of the target temperature would be indirectly detected. The first modification that a titanium target could encounter is the $\alpha$-Ti to $\beta$-Ti phase transition occurring at $882^{\circ} \mathrm{C}$ $[16,17]$. Below this critical temperature, the discharge parameters would remain unchanged and neither the rise of the target temperature nor the modification of the deposition condition at the substrate level would be suspected. However, based on our data, it appears that the deposition conditions at the substrate are modified as IR photons are produced by the relatively hot target (even if the target backside is cooled). This is particularly true for a HiPIMS discharge produced with the balanced magnetic field. This energetic contribution should not be neglected with respect to the one originating from the bombardment by the plasma species. The influence of the IR flux on the film growth mechanism would be relatively significant depending on the IR absorption efficiency of the deposited material.

\subsection{Influence of the magnetron power in DCMS}

Energy flux measurements were performed in front of the Ti target in UB-DCMS discharge at a pressure of $0.66 \mathrm{~Pa}$ and for different powers applied to the magnetron cathode. The HFM 
signals and the fits of the IR-related parts of the curves are given in Fig. 4 a) and b), respectively. Values of plasma and IR contributions are presented in table 2 together with their proportion, the characteristic time, and the target surface temperature.

It appears that both the plasma and the IR contributions increase with power. This could be explained by the rise of the ionisation rate of the plasma as the power increases. The later situation causes: i) a rise of the number of ions interacting with the substrate, and ii) an enhanced heating process of the target surface through ion bombardment. However, the part of the input power dissipated in target heating slightly evolves versus the power since the ratio of the IR contribution to the global energy transfer also increases (see table 2).

It is interesting to note that values of the characteristic time are close (between 6 and $9 \mathrm{~s}$ ) to each other whatever the power applied during the DCMS discharge. This result indicates that the corresponding heating rates of the target surface are similar.

The target temperature increases linearly with the input power as shown in table 2 . It reaches several hundreds of degrees even at low power values (below 100W). On Fig. 5, IR emission and plasma contributions are plotted versus the input power. It is seen that the former evolves linearly with the power, whereas for the latter a power 4 law is evidenced, related to the $\mathrm{T}^{4}$ expected evolution (continuous line).

5. Conclusion

The total energy flux delivered on the substrate, during magnetron sputtering, was successfully measured. We have demonstrated that two components are involved: a fast contribution which is attributed to collisional mechanisms and a slower one which is attributed to IR emission emanating from the heated sputtering target surface. The evolution of the radiative energy flux was studied depending on the plasma-target surface interactions. This was performed by varying the discharge parameters such as the cathode magnetic field configuration (balanced or unbalanced), the sputter power, and the discharge type (DC, pulsed-DC and HiPIMS).

From all studied cases, it appears that, when the target surface is heated at moderate temperature (i.e. temperatures lower than the value for which severe modification of the target surface can influence the sputtering discharge) the substrate could be submitted to a non- 
negligible IR radiation flux. This contribution increases with the power supplied to the cathode and in pulsed regime, because the ion flux at the target surface rises, inducing a more efficient heating process of the target surface. The characteristic time of heating $(\tau)$ is related to the target surface heating rate which depends on: the incoming energy flux, the thermal conductivity of the metal, the cooling process efficiency and the duty cycle. In the case of HiPIMS with a B magnetic field, a huge amount of energy is transferred to the target during the pulse $\mathrm{ON}$ time and the time to reach thermal equilibrium is relatively long. The contribution of the IR radiation is so important that we believe it might influence the deposition process and thus, modify the final characteristics of the film. It can be expected that this effect would depend on the optical properties of both the substrate and the deposited film.

This energetic contribution is rather difficult to detect and to quantify by conventional discharge analysis techniques and is usually not taken into account in the discussion related to the plasma - thin film growth process. In consequence, we believe that the data reported in the present manuscript could be of general relevance for discussing the thin film growth mechanisms.

Authors thank the COST action MP804 for financial support. S. Konstantinidis is Research Associate of the National Fund for Scientific Research (FNRS, Belgium).

A. Balhamri, S. Konstantinidis, and R. Snyders thank the financial support of the Belgium Government through the Pôle d'attraction Inter Universitaire" (PAI, P6/08, Plasma Surface Interaction").

\section{References}

[1] J. Han, J. Phys. D: Appl. Phys. 42 (2009) 043001.

[2] S. Mahieu, P. Ghekiere, D. Depla, R.D. Gryse, Thin Solid Films 515(2006) 1229.

[3] D. Mercs, C. Petitot, A. Duranteau, V. Demange, C. Coddet, Plasma Process.Polym. 4 (2007) S175.

[4] A.L. Thomann, N. Semmar, R. Dussart, J. Mathias, V. Lang, Rev. Sci. Instrum. 77 (2006) 033501 . 
[5]R. Dussart, A.L. Thomann, L.E Pichon, L. Bedra, N Semmar, P. Lefaucheux, J. Mathias, Y. Tessier, Appl. Phys. Lett. 93 (2008) 131502.

[6] P.A. Cormier, M. Stahl, A.L. Thomann, R. Dussart, M. Wolter, N. Semmar, J. Mathias, H. Kersten, J. Phys. D: Appl. Phys. 43 (2010) 465201.

[7] L. Bedra, A.L. Thomann, N. Semmar, R. Dussart, J. Mathias, J. Phys. D: Appl. Phys. 43 (2010) 065202.

[8] S. Abolmasov, P.A. Cormier, A.T. Rios, R. Dussart, N. Semmar, A.L. Thomann, P.R. iCabarrocas, Appl. Phys. Lett.100 (2012) 011601.

[9] S. Konstantinidis, J. Dauchot, M. Ganciu, A. Ricard, M. Hecq, J. Appl. Phys. 99 (2006) 013307.

[10] P.-A. Cormier, A. Balhamri, A.-L. Thomann, R. Dussart, N. Semmar, J. Mathias, R. Snyders, and S. Konstantinidis, J. Appl. Phys. 113 (2013) 013305

[11] Jun. Xu and R.A. Wirtz, IEEE Trans. Compon. Packag. Technol. 25 (2003) 615-620

[12] David R. Lide, Handbook of chemistry and physics, 73rd edition. CRC Press, INC., 1992 - 1993.

[13] D. Bartz, P.M. Chung, F.M. Devienne, A.B. Metzner, E.M. Sparrow, Advances in heat transfer (1965) Academic Press.

[14] K. Sarakinos, J. Alami, S. Konstantinidis, Surf. Coat. Technol. 204 (2010) 1661.

[15] A. Anders, J. Vac. Sci. Technol. A 28 (2010) 783.

[16] J. Tesar, J. Martan, J. Rezek, Surf. Coat. Technol. 206 (2011) 1155.

[17] D. Mercs, F. Perry, A. Billard, Surf. Coat. Technol. 201(2006) 2276. 
Figure captions

Fig. 1. Mapping of the magnetic field between the target surface and the substrate $(8 \mathrm{~cm})$ for a) the unbalanced magnetron cathode and b) the balanced one. The black lines underlining the field lines are added as a guide to the eye.

Fig. 2. Energy flux evolution with respect to time during balanced a) and unbalanced b) pDCMS at $0.66 \mathrm{~Pa}$ and a $400 \mathrm{~W}$ averaged power. The black line in a) corresponds to the fit of the IR part using equation (1). Parameters present in equation 1 are represented: $\varphi_{\text {coll }}$, $\varphi_{\text {radeq }}, \varphi_{5^{\circ} \mathrm{C}}$, are the energy flux due to collisional processes, the energy flux due to IR emission when the thermal equilibrium is reached, and the energy flux due to radiative transfer between the HFM surface at $5^{\circ} \mathrm{C}$ and the chamber walls at ambient temperature, respectively. The energy flux at the thermal equilibrium $\left(\varphi_{\mathrm{eq}}\right)$ is also represented.

Fig. 3. Energy flux evolution with respect to time during balanced DCMS (a), pDCMS (b) and HiPIMS (c) discharges at $0.66 \mathrm{~Pa}$ and a $400 \mathrm{~W}$ averaged power. For pDCMS and HiPIMS discharges the results were fitted in order to access to an energy flux equilibrium value.

Fig.4: Energy flux density in B DCMS discharges for $100 \mathrm{~W}, 200 \mathrm{~W}$ and $800 \mathrm{~W}$ at $0.066 \mathrm{~Pa}$ argon pressure: a) measurements, b) fits of the IR contribution.

Fig. 5: Evolution of IR and plasma contributions with respect to the input power (graphs plotted from table 2 data).

Fig. 6: Energy flux evolution with respect to time in HEA experiment. Energy flux was alternatively monitored for each target with a $200 \mathrm{~W}$ constant plasma power. 
Figure 1a

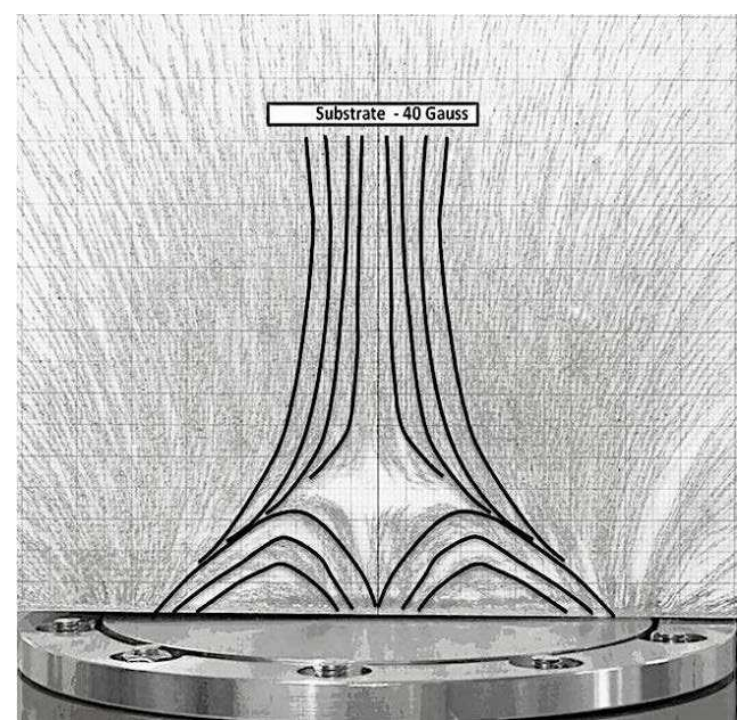

Figure $1 b$

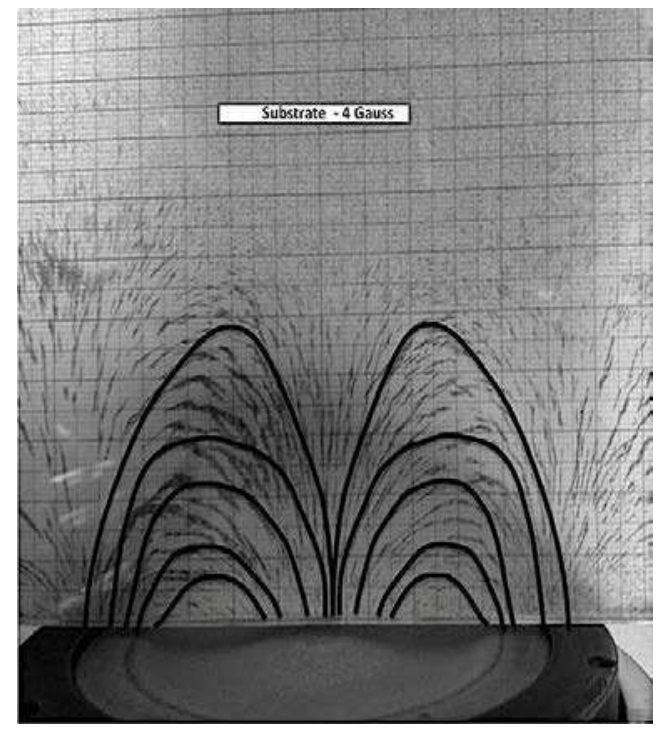


Figure 2a

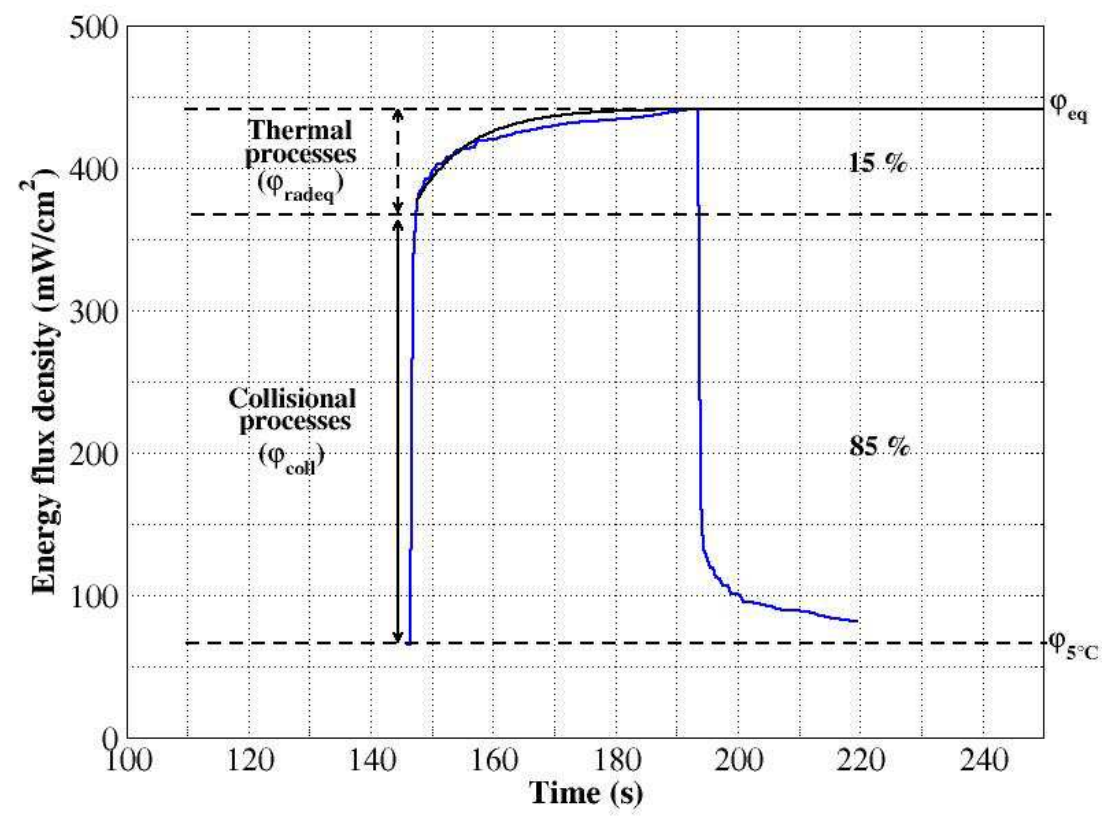

Figure $2 b$

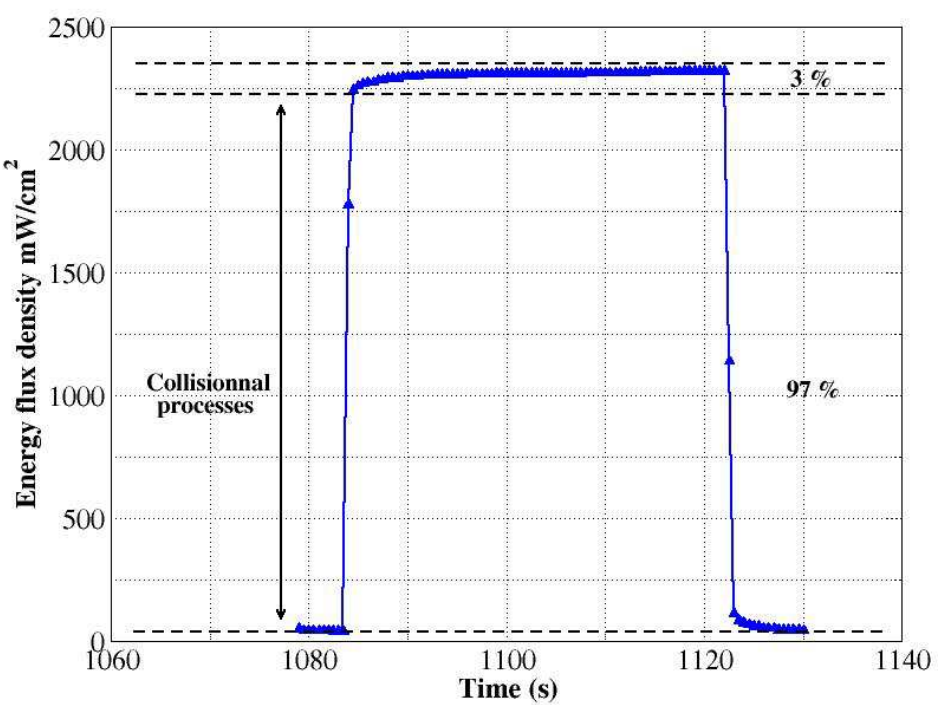


Figure 3
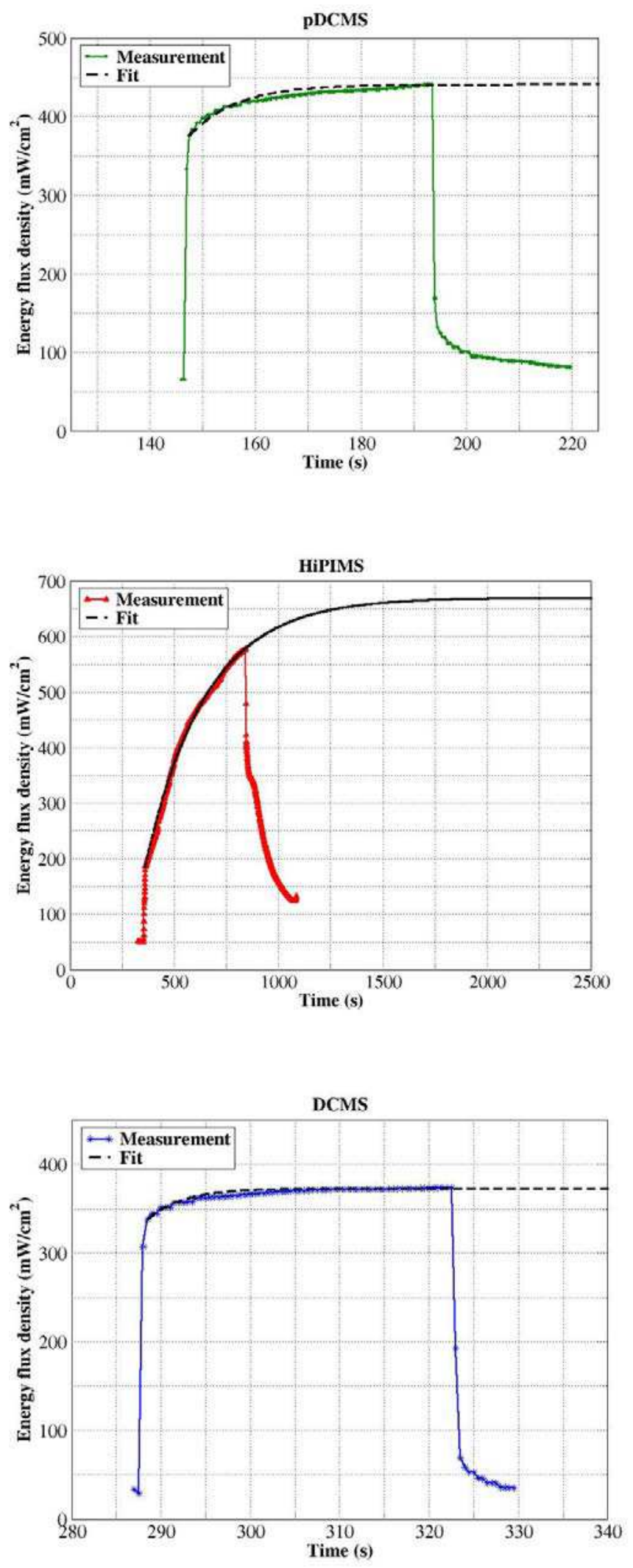
Figure $4 \mathrm{a}$

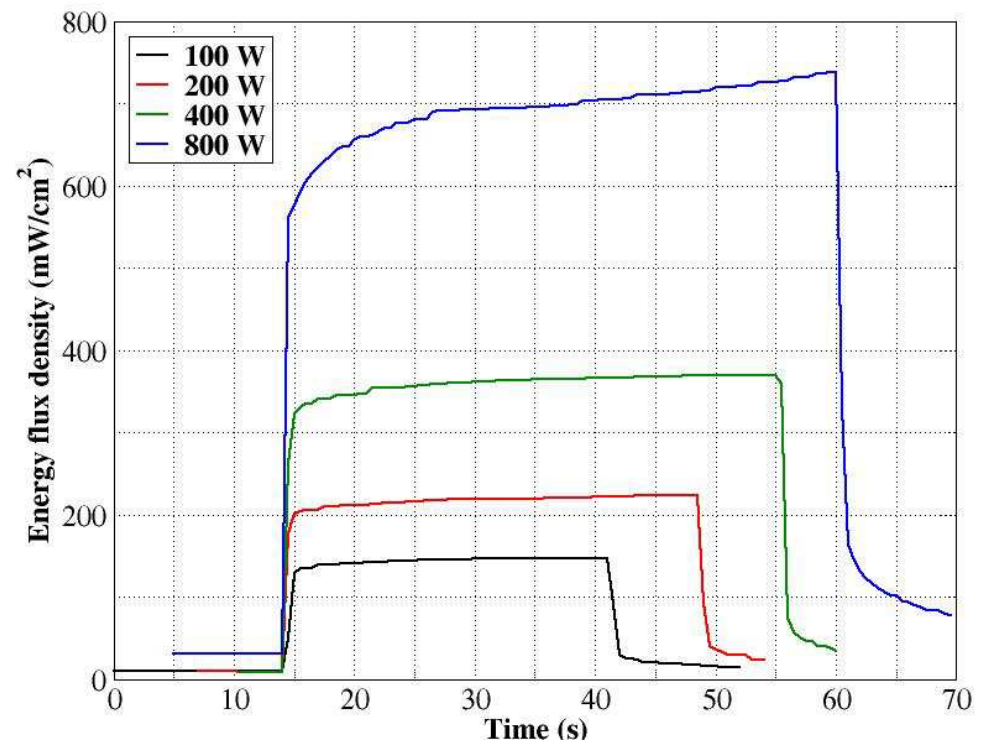

Figure $4 b$

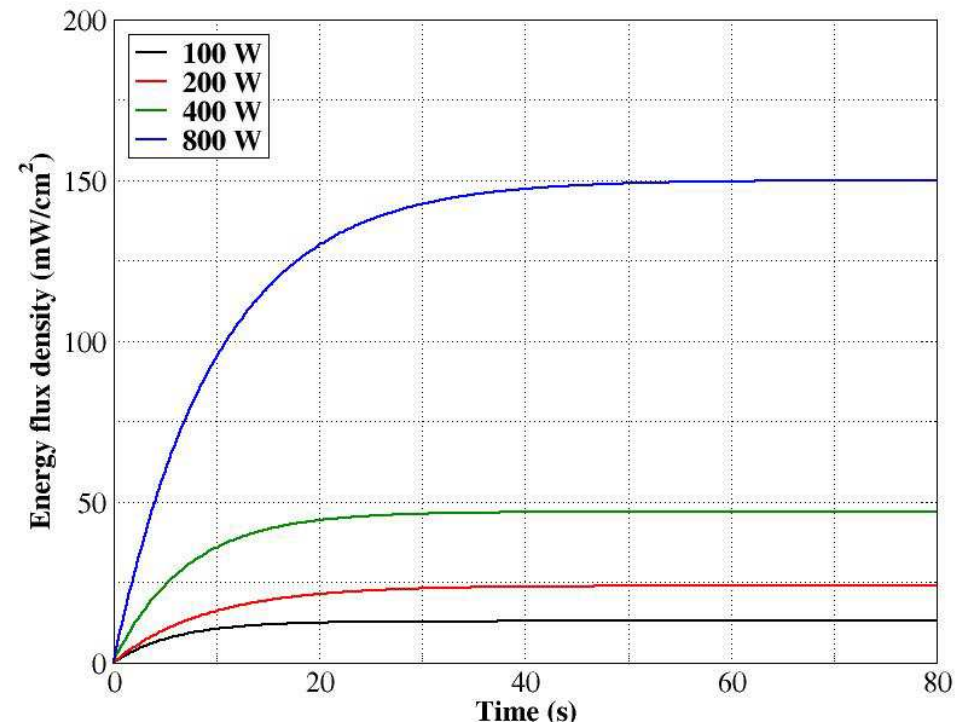




\section{Figure 5}

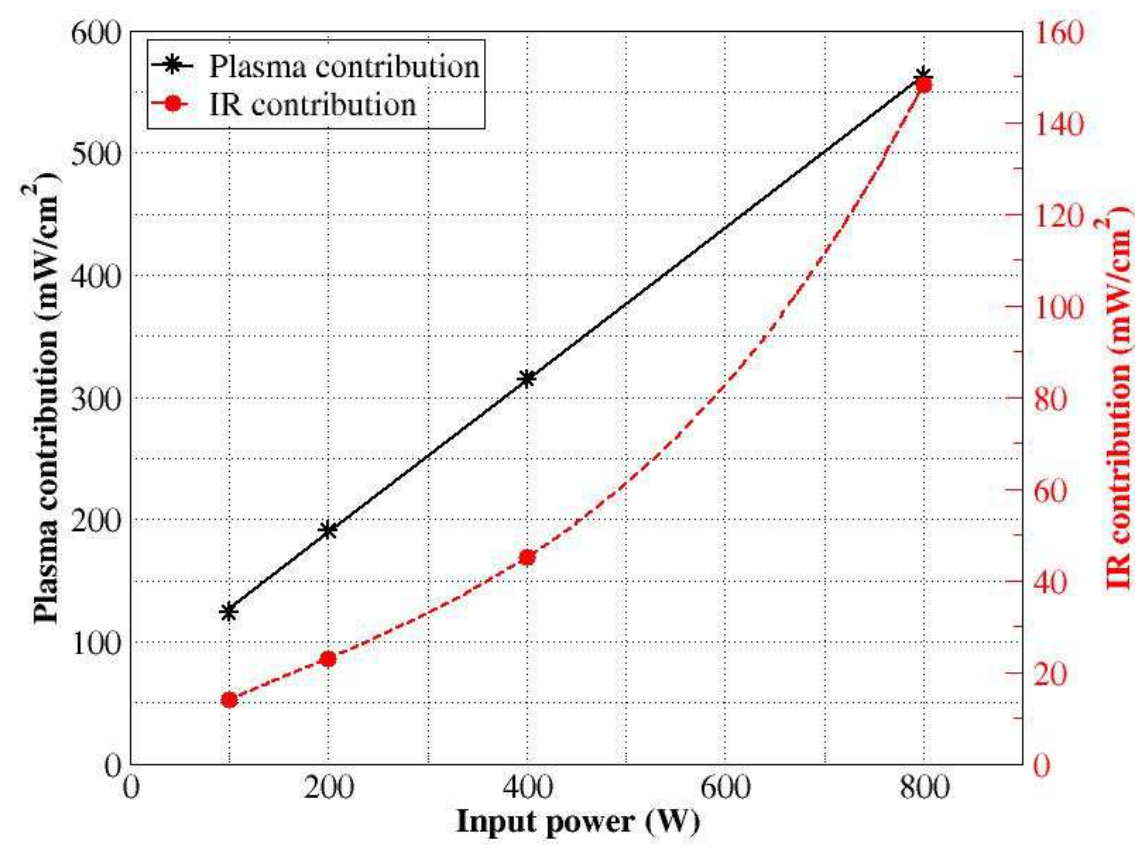


Table captions

Table 1: HiPIMS and pDCMS parameters used for the study of the influence of each discharge type at an argon pressure of $0.66 \mathrm{~Pa}$ and a mean power of $400 \mathrm{~W}$

\begin{tabular}{|c|c|c|}
\hline Parameters & HiPIMS & pDCMS \\
\hline Peak power $(\mathbf{k W})$ & 20 & 420 \\
\hline Pulse ON time $(\boldsymbol{\mu s})$ & 20 & 18.8 \\
\hline Pulse OFF time $(\boldsymbol{\mu s})$ & 480 & 1.2 \\
\hline Repetition rate $(\mathbf{k H z})$ & 1.950 & 50 \\
\hline Duty cycle $(\%)$ & 4 & 95 \\
\hline
\end{tabular}

Table 2: Plasma and IR contributions depending on the supplied power in DCMS discharges, proportion of each contribution to the global energy transfer, values of $\tau$ obtained from the fit of the IR part, and target surface temperature estimated from equation (2).

\begin{tabular}{|c|c|c|c|c|c|c|}
\hline $\begin{array}{c}\text { Discharge } \\
\text { type / } \\
\text { Power (W) }\end{array}$ & $\begin{array}{c}\text { Plasma } \\
\text { contribution } \\
(\mathrm{mW} / \mathrm{cm} 2)\end{array}$ & $\begin{array}{c}\text { IR } \\
\text { contribution } \\
(\mathrm{mW} / \mathrm{cm} 2)\end{array}$ & $\begin{array}{c}\text { Total energy } \\
\text { flux } \\
\text { (mW/cm2) }\end{array}$ & $\begin{array}{c}\text { Percentage } \\
\text { of IR } \\
\text { emission }\end{array}$ & $\tau(\mathbf{s})$ & $\begin{array}{c}\text { Target } \\
\text { surface } \\
\text { temperature } \\
\left({ }^{\circ} \mathrm{C}\right)\end{array}$ \\
\hline $\begin{array}{c}\text { B_DCMS- } \\
100\end{array}$ & 124 & 14 & 138 & $9.5 \%$ & 7 & 211 \\
\hline $\begin{array}{c}\text { B_DCMS- } \\
200\end{array}$ & 191 & 23 & 214 & $10.3 \%$ & 8 & 269 \\
\hline $\begin{array}{c}\text { B_DCMS- } \\
400\end{array}$ & 315 & 45 & 360 & $12.2 \%$ & 6 & 362 \\
\hline $\begin{array}{c}\text { B_DCMS- } \\
800\end{array}$ & 562 & 148 & 710 & $20 \%$ & 9 & 577 \\
\hline $\begin{array}{c}\text { B_pDCMS- } \\
400\end{array}$ & 376 & 65 & 441 & $15 \%$ & 9 & 420 \\
\hline $\begin{array}{c}\text { UB_pDCM } \\
\text { S-400 }\end{array}$ & 2231 & 69 & 2300 & $3 \%$ & 4 & 705 \\
\hline $\begin{array}{c}\text { B_HiPIMS- } \\
400\end{array}$ & 160 & 607 & 667 & $76 \%$ & 289 & 870 \\
\hline
\end{tabular}


